\title{
Los Animales EN LA WiK'UÑA DE Cecilia Vicuña: Figuras Opuestas Y COMPLEMENTARIAS*
}

Fecha de Recepción: 6 de marzo de 2013

Fecha de aprobación: 21 de mayo de 2013

\section{Resumen}

El presente trabajo consiste en un análisis del poemario $L a$ Wik'uña (1990), de la poeta chilena Cecilia Vicuña (1948), enfocado en las figuras de los animales poetizados y su vinculación con la cultura indígena andina, en especial con el principio de dualidades complementarias Hanan / Hurin, el que se puede traducir como "Alto" y "Bajo". Las imágenes poéticas se analizan desde un soporte antropológico, a fin de demostrar la asimilación de los saberes indígenas en la obra de la poeta chilena.

Palabras clave: Cecilia Vicuña, $L a$ Wik’uña, poesía chilena, animales, Hanan / Hurin.

* Este artículo de reflexión forma parte de mi tesis doctoral en Literatura Latinoamericana por la Universidad de Concepción, Chile, la que se titula "Gabriela Mistral, Violeta Parra, Cecilia Vicuña y Soledad Fariña: poéticas de las artes múltiples e integradas" (2013).

Citar: Ariz Castillo, Y. (Julio-Diciembre de 2013). Los animales en la Wik'uña de Cecilia Vicuña: figuras opuestas y complementarias. La Palabra(23), 51-62.

\section{Yenny Ariz Castillo}

Universidad Adventista de Chile yennyariz@gmail.com

Profesora de Español, Magíster en Artes con mención en Literaturas Hispánicas y Doctora en Literatura Latinoamericana por la Universidad de Concepción, Chile. Actualmente es docente de la Universidad Adventista de Chile. 


\title{
ANIMAL IS IN LA WIK'UÑa [THE WIK'UÑa] BY CECILIA VICUÑA: OPPOSITE AND COMPLEMENTARY FIGURES
}

\begin{abstract}
This work consists on an analysis of the Chilean poetry female writer Cecilia Vicuña's book La Wik'uña (1990), focused on the figures of poetized animals and its relation with Andean indian culture, especially with the duality principle Hanan/ Hurin, which means "High" and "Low". The poetic images are studied from an anthropological point of view, looking for demonstrating the assimilation of Indian knowledge in the work of this Chilean female poet.
\end{abstract}

Key words: Cecilia Vicuña, La Wik’uña, chilean poetry, animals, Hanan / Hurin.

\section{Les Animaux Dans la Wik'uña de Cecilia VicuÑa: Des FiguRES OPPOSEES ET COMPLEMENTAIRES}

\section{Résumé}

Ce travail est une analyse de l'écueil de poèmes La Wik'uña (1990), de la femme poète chilienne Cecilia Vicuña (1948), focalisée sur les figures des animaux poétisés et leur lien avec la culture indigène andine, spécialement avec le principe de dualités complémentaires Hanan / Hurin, qui peut se traduire comme « Haut » et «Bas ». Les images poétiques sont analysées à partir d'un support anthropologique, dans le but de démontrer l'assimilation des savoirs indigènes dans l'œuvre de la femme poète chilienne.

Mots Clés: Cecilia Vicuña, La Wik’uña, poésie chilienne, animaux, Hanan / Hurin 
Cecilia Vicuña (1948), poeta y artista visual chilena, se caracteriza por una abundante producción poética, además de sus performances, instalaciones, pinturas y otros trabajos artísticos ${ }^{1}$. En sus primeros poemarios, Sabor a mi (1973), Siete poemas (1979) y Luxumei, el traspié de la doctrina (1983), se destaca la poetización del cuerpo y del erotismo. Sin embargo, el interés permanente de Vicuña por las cosmovisiones indígenas la condujo a una búsqueda literaria, lingüística y espiritual de una visión del mundo en las cosmogonías altiplánicas, la que se ha manifestado en sus siguientes obras, desde Palabrarmas (1984) en adelante ${ }^{2}$.

Las lecturas de Vicuña acerca de las culturas ancestrales se complementaron con vivencias que le acercaron de forma definitiva a los saberes indígenas americanos. En Colombia, la escritora tuvo la primera experiencia directa con la cultura indígena andina. En una entrevista personal que sostuvimos el año 2010, me comentó la relevancia de este período para su formación como artista:
Fue impactante presenciar la relación con la tierra y con la espiritualidad de las comunidades indígenas del altiplano. Estuve en distintas regiones. El primer trabajo que hice fue con una comunidad indígena del Valle del Cauca, la parte estrictamente andina. Esta comunidad me invitó a que yo hiciera un taller con los niños. El museo de folclor de Bogotá me pidió que hiciera una exposición del arte guambiano, organizada por la propia comunidad, sin curador (Ariz, 2010, s.p.).

Es así como la crítica acerca de su poesía se ha hecho cargo de su vínculo con las culturas indoamericanas. Eugenia Brito en el prólogo a Antología de poetas chilenas. Confiscación y silencio (1998) destaca la calidad de experimento de los textos de Vicuña, en cuanto a temas y a forma, así como también su exploración de aspectos de la existencia olvidados por la cultura occidental. Afirma:

Cecilia Vicuña es la figura que intentará a partir de los objetos abandonados, o del conjuro mágico de las palabras, hacer una memoria $y$ no sólo eso, sino toda una religión en que el lenguaje se una a lo sagrado, reinsertando en ese espacio los lugares olvidados por la cultura occidental, mejor dicho, los lugares que han pretendido ser exterminados o abolidos por ella (p. 12).

En concordancia con esta aproximación, la poeta Soledad Fariña se refiere en específico al poemario $L a$ Wik'uña (1990) en su libro Una reflexión mestiza desde la escritura de cuatro mujeres chilenas (1995); en la obra de Vicuña, Fariña percibe una pregunta por nuestra identidad cultural como latinoamericanos, referida a "aquellos signos y valores que han quedado como monumentos mudos, pero a la vez sugerentes de una espiritualidad peculiar" (p. 15), en tanto lo que se propondría Vicuña sería la recuperación de lo sagrado, a través de la metáfora del animal andino, la vicuña.

Efectivamente, La Wik'uña es uno de los poemarios de Vicuña que destaca por la recreación de la cosmovisión inca, así como también recupera otras culturas americanas, entre las que sobresale la guaraní. Su

1 Vicuña ha publicado quince poemarios, entre los que destaco: Sabor a mí (Inglaterra, Beau Geste Press, 1973, reeditado por Universidad Diego Portales el año 2007), Luxumei o el traspié de la doctrina (México, Oasis, 1983), Precario/Precarious (Estados Unidos, Tanam Press, 1983), Palabrarmas (Argentina, El Imaginero, 1984, reeditado por RIL Editores el año 2005), Samara (Colombia, Museo Rayo, 1987), La Wik'uña (Chile, Francisco Zegers Editor, 1990), Palabra e Hilo / Word E Thread (Escocia, Mornig Strar Publications, 1996), y la antología Soy Yos 1966-2006 (Chile, Lom, 2011), selección de poemas realizada por la autora en conjunto con el estudioso Naín Nómez.

2 Para Bianchi (1990), Vicuña pertenece a la generación de poetas chilenos de 1970 y se caracteriza por una "poesía visiva, donde la palabra se une a la fotografía, al dibujo, al material plástico o al graffiti” (p. 74). Sin embargo, tanto Arrate (2002) como Teresa Calderón, Lila Calderón y Tomás Harris (1996) la ubican en la generación de 1960, que se caracterizaría por una poesía de resistencia, con un discurso desacralizado y desmitificador (1996, pp. 14-15). 
título corresponde al término quechua para designar a la vicuña (Lama vicugna), camélido sudamericano hermoso y grácil, que habita las cumbres más aisladas y elevadas de los Andes (Flores Ochoa, 1968, p. 21). En efecto, los animales cumplen un rol esencial en la obra, debido a su relevancia en la cosmovisión andina, pues implican un ejemplo para el ser humano:

Pero el animal es para el indio algo más que la representación de un espíritu: es un ejemplo. El comportamiento de los animales en su cotidianidad: cómo cazan, cómo comen, cómo juegan, cómo duermen, todo es para el aborigen una sabiduría natural que incorpora a su propia vida. Por eso para él los animales son seres importantísimos a los que es necesario cuidar (Martínez, 2004, p. 51).

En la obra de Vicuña, se distinguen cuatro animales relevantes para las cosmovisiones indígenas americanas: la vicuña, el zorro, el colibrí y el jaguar. Los cuatro se vinculan con uno de los elementos de la cosmovisión andina que estructura el poemario, el principio Hanan / Hurin, confor- mado por vocablos quechuas que significan: "Alto y bajo. Oposición complementaria de las comunidades y pueblos andinos divididos en dos sectores" ("Glosa", p. 1013). Sin embargo, la mencionada bipartición tiene connotaciones mayores que las del espacio. Luis Alberto Reyes (2009), estudioso del pensamiento indígena, comenta:

Esta dualidad tiene dos referencias básicas: una es la del Cielo o las partes altas de la Tierra contrapuestas a sus profundidades y partes bajas como son las costas y valles, y la otra es la relación de oposición y complementariedad entre dos partes de una comunidad, autoridad o pareja (en este último caso la complementariedad suele adoptar otros nombres) (p. $171)^{4}$.

Según Reyes, tanto la geografía como las relaciones de poder se asumen en virtud de dualidades complementarias, de tal manera que todo el mundo constituye "un hilván" de conexiones entre elementos opuestos complementarios. Es necesario aclarar que remarco el vocablo "hilván" pues las metáforas del hilo, el hilván y el tejido son constantes en la obra de Vicuña, y la autora las aprehende de su cercanía con las cosmovisiones indígenas.

En la obra que analizo, las ideas del tejido y del hilván resultan palmarias, pues el poemario redunda en metáforas acerca del hilo, el tejido, la lana y la acción de tejer. A modo de ejemplo, en el siguiente texto de La Wik'uña aparece la imagen del tejido, y se manifiesta su capacidad de reunir todo, incluso, lo opuesto / complementario:

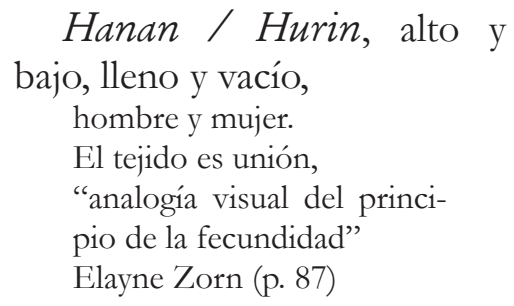

En correspondencia con la cosmovisión americana, el tejido encarna la totalidad en la obra de Vicuña, así como también lo fecundo y creativo, gracias a la inclusión del aporte del texto de Zorn (1952-2010), antropóloga estudiosa de los textiles ${ }^{5}$.

En la obra, los animales también están "tejidos" o "hilvanados" poéticamente en una

3 "Glosa" es un glosario de términos que Vicuña incluye en la obra que analizo. Todas las citas de La Wik'uña están tomadas de la única edición del texto, de 1990. En adelante se citarán el número que le corresponde a los versos y la página. En el caso de citar un texto completo, se indicará su nombre y la página.

4 Por su parte, Granda Paz (1998) ahonda en el origen de esta bipartición, que para él surge con la pareja de gemelos, presente en los mitos cosmogónicos de los Andes: "La pareja de gemelos (...) constituye la fuente pilar en la que se construye la visión dual de los indígenas de los Andes, desprendiéndose desde allí concepciones como la bipartición del espacio en los Hanan y Hurin y toda una larga serie de oposiciones: blanco/negro, vida/muerte, sol/luna, positivo/negativo, lo físico y lo espiritual, etc., pero estas oposiciones no lo son en el sentido de contradicción, sino de complementariedad" (p. 24).

5 Uno de los rasgos discursivos de La Wik'uña es la inclusión de citas de antropólogos, chamanes y estudiosos de las culturas indígenas, que se integran al texto poético. 
red de significados, que los dispone de acuerdo al principio Hanan / Hurin. Flores Ochoa en Pastores de la Puna $(1977)^{6}$ explica que para los andinos, los animales "han sido dados a la humanidad por la Pachamama, a través de los $A p u^{7}$ o $P a$ raje de cada lugar que actúan como intermediarios" (p. 229, cursivas del texto).

Al constituir un regalo de las deidades, los animales son tratados con especial cuidado, por lo que existe una "ley espiritual" que los divide en domésticos y silvestres ${ }^{8}$, entre estos últimos se cuenta la vicuña, el zorro y los pumas (jaguares). De esta manera, el ser humano conforma sus rebaños con los animales domésticos, mientras los silvestres constituyen el rebaño de los $A p u$ :

Por ser animales silvestres forman los rebaños de los Apu, son su propiedad y le sirven de la misma manera como lo hacen con el hombre los animales domesticados. Las vicuñas son como alpacas porque le dan lana; la taruka [venado andino] son como las llamas porque transportan las cargas (...) $\mathrm{El}$ zorro es el equivalente silvestre del perro y ayuda al $A p u$ en el cuidado de los rebaños (...) los pumas recuerdan a los gatos. (Flores Ochoa, 1977, pp. 229-230)

Transgredir esta ley, es decir, apropiarse indebidamente del rebaño de los $A p u$, puede traer serias consecuencias; por ejemplo, entre los pastores de Paratía (Perú) ${ }^{9}$ existe la creencia de que quienes le dan muerte a una vicuña "sufrirían los peores daños personales y familiares (...) Del mismo modo, no se deben matar zorrinos y búhos, aunque a veces basta verlos para que un pariente muera" (Flores Ochoa, 1968, p. 96).
No obstante, la suavidad de la fibra de la vicuña, superior a la de todos los animales (Flores Ochoa, 1977, p. 114) y su alto valor en el mercado, llevó a su caza indiscriminada ${ }^{10}$, lo que fue mermando la cantidad de ejemplares hasta llegar al peligro de extinción, por lo que los países afectados han elaborado leyes y proyectos de conservación de la especie ${ }^{11}$.

Parte de los animales poetizados en La Wik'uña pertenecen al rebaño de los $A p u$, las vicuñas y los zorros, grupo al que se integran dos animales de la cosmogonía guaraní, el colibrí y el jaguar. Las especies mencionadas se asocian en parejas que permiten apreciar el principio de complementariedad que rige el texto:
Unión complementaria, pa- ridad La extrema fuerza y la debilidad El colibrí y el ja- guar La wik'uña y el zorro

6 Texto citado por Vicuña en su poemario, que corresponde a un conjunto de artículos de diversos autores sobre el pastoreo en altura de Perú, con énfasis en los aspectos económicos, ecológicos y culturales; se estudia a comunidades campesinas de las décadas de los sesenta y setenta, cuyas costumbres atravesaron el proceso de hibridación indígena-español.

7 "Apu tiene dos acepciones: La primera, para referir a la naturaleza sacralizada, dueña de los animales, plantas silvestres y del agua, está representada por las montañas o cerros tutelares. La segunda, refiere la jerarquía social como sinónimo de acaudalado, rico, poderoso" ( García, 1996, p. 104).

8 "Se conocen dos especies silvestres de camélidos sudamericanos, la vicuña (Lama vicugna) y el guanaco (Lama guanicoa). Las domesticadas son la alpaca, llamada también paqo y paqocha (Lama pacus) y la llama (Lama glama)" (Flores Ochoa, 1977, p. 36).

9 Flores Ochoa en Los pastores de Paratía: una introducción a su estudio (1968) se refiere a las costumbres de una comunidad de pastores de la zona de Paratía (Provincia de Lampa del departamento de Puno, en la parte meridional del Perú), cuya altura promedio está sobre los 4.300 metros sobre el nivel del mar.

10 La comunidad de Paratía le comentó a Flores Ochoa (1968) en la década del sesenta que: "grupos de comerciantes especializados que vienen de Juliaca, Lampa, Huancané, Arequipa e incluso dicen de Bolivia (...) por temporadas recorren Paratía comprando (...) en forma ilícita y subrepticia lana de vicuña, siendo -por tanto- los causantes indirectos de su exterminio" (p. 137). A pesar de lo que afirma Flores Ochoa, López Austin y Millones (2010) señalan que los incas sacrificaban vicuñas en la fiesta denominada Inti Raimi, ritual que se justifica de la siguiente manera: "en esta fiesta los sacrificios de animales incluían a los domésticos (llamas y alpacas) y a los silvestres (guanacos, venados y vicuñas), como indicando que la celebración abrazaba el universo de los hombres y el desconocido de los animales silvestres" (p. 263).

11 Argentina, Bolivia, Chile, Ecuador y Perú han creado leyes, mecanismos de control de caza y diversas estrategias para la recuperación de la especie. Al respecto ver Lichtenstein, Oribe, Grieg-Gran y Mazzucchelli (2002). 
La presa y el predador (vv. 1-5, p. 97).

A continuación, me centraré en estas parejas de animales, a fin de demostrar la disposición poética de sus figuras en la obra, de acuerdo al principio Hanan / Hurin.

\section{La vicuña y el zorro: una historia de amor}

En el poema "La wik'uña", el animal andino, cuyo nombre se escribe siempre en quechua, se identifica con su acción: "La wik'uña / es pastar y correr" (vv. 1-2, p. 21). La sencillez y las costumbres del animal se dan a conocer, a la vez que se reconoce su majestad y sacralidad: "Señora de las / altitudes andinas" (vv. 39-40, p. 23); su grácil figura se funde con su entorno: "Cúspido brote / a todo dar" (vv. 5-6, p. 21), en estos versos, el neologismo "cúspido" se asimila a "cúspide", y "brote" a "trote", es decir, el trote "a todo dar" de la vicuña, en las cúspides y entre los brotes.

El texto le atribuye diversas cualidades a la vicuña, algunas de ellas asociadas a la luz, y al carácter de ofrenda:

Pensar lumínico y cabal

Fase de hilo Entrando en el cristal Fibra de orar

(vv. 18-23, p. 22).
La lana de la vicuña es sagrada para la hablante ("Fibra de orar") por su contacto con la luz, presente a partir del "pensar lumínico" identificado con la "fase de hilo" (vicuña) que entra en el cristal (¿el sol?, ¿el agua?); los versos sugieren el efecto de iridiscencia a partir de la figura de la vicuña en la que la luz se refleja.

Además, el animal se metaforiza con míticos afluentes de la zona andina:

Tú eres la Uru y la Bamba Qué andas haciendo Apu aquí Oro en monte Rimac allá12 (vv. 46-51, p. 23).

El juego con el nombre del río Apurimac connota el movimiento de la vicuña y su valor para los andinos, así como también el desplazamiento de la voz de la deidad, pues el $A p u$ -dios- transita por los montes, al igual que el "oro" que habita en ellos, la vicuña, y la connotación ritual del lenguaje poético en interrelación con la naturaleza ("oro" es también una forma verbal de "orar").

Asimismo, en el poema abundan diversos juegos fónicos, neologismos y onomatopeyas que, entre otros aspectos, enfatizan los continuos desplazamientos de la vicuña por los cerros: "Pálpita pálpita / saltarina" (vv. 37-38, p. 23).
En el poema, la hablante interpela a la vicuña, enunciando "Me duermo / en tu potestad" (vv. 12-13, p. 21). Los versos implican una relación estrecha con el animal, quien transmite confianza a la hablante; sin embargo, la imagen de la Vicuña también plantea interrogantes, en tanto la hablante busca su propio lugar en ese entorno sagrado): "¿A qué te soy?" (v. 67, p. 24), lo que quizás puede entenderse como ¿quién soy para ti? o ¿cómo puedo servirte?

El texto finaliza con una pregunta, que implica finalmente la complejidad de la cosmovisión andina, la que tal vez jamás lleguemos a entender cabalmente: "¿a qué has venido?" (v. 73, p. 24), pregunta formulada ¿para el animal? -¿cuál es el sentido de su existencia entre las alturas?- o ¿para la hablante? -¿qué busca ella en los cerros y en la imagen de la vicuña?

El doble complementario de la vicuña es el zorro; por ello, el poema "Aguará", que sucede a "la wik'uña", se refiere a este animal salvaje, un tipo de cánido (zorro) de las zonas andinas, guardián de los rebaños del $A p u$. El poema está dedicado al pintor argentino César Paternosto, con quien la poeta comparte su vida y este acercamiento hacia lo andino,

12 Urubamba es un “afluente del Amazonas, llamado Willkamayu, 'río sagrado' (quechua). En la parte superior de su curso bordea Ollantaytambo y Macchu Picchu". Apurímac es un "Río que une al Urubamba para formar el Ucayali"; su nombre significa "señor que habla" ("Glosa", p. 101). 
hecho patente en La Wik'uña, pues la poeta declara en una nota anexa al poemario, titulada "Gratitud", que esta obra se escribió "en paralelo" con el libro que redactó su marido, Piedra abstracta. La escultura inca: una visión contemporánea (1989)

"Aguará" es el único poema de la obra que posee dedicatoria. En entrevista con la poeta, le comenté los alcances que me sugiere este homenaje:

En relación con esta experiencia compartida [escribir en paralelo sobre lo andino], La Wik'uña es también una historia de amor, al estar César Paternosto presente en el libro, analogado con un zorro.

Claro, esta historia de amor sucede tanto en Perú como en Nueva York, en realidad es una historia de amor que hace una triangulación: Nueva York, Buenos Aires, el Andes chileno... Lo principal sucede entre Cusco, Buenos Aires y Nueva York (Ariz, 2010, s.p.).

La experiencia de unión y de escritura en paralelo de Vicuña y Paternosto se analoga en la relación vicuña-zorro, como opuestos complementarios; la hablante se refiere con ternura al aguará, mostrando una estrecha conexión con él: "Tú eres mi casa / y cintura"

(vv. 3-4, p. 25) y la complementariedad de ambos se metaforiza con distintos elementos: "Mosca a la miel / color al pincel" (vv. 11-12, p. 25). Los rápidos desplazamientos del zorro se evidencian en el texto: "Y en la cola / te revolotean aviones" (vv. 9-10, p. 25), imagen que une lo natural y lo tecnológico. La pintura y la antropología, intereses de $\mathrm{Pa}$ ternosto, se manifiestan en los versos, así como también su investigación en Ollantaytambo y otros sitios arqueológicos:

\begin{abstract}
Wari y Nazca vuelve a comer Entra al templo pórfido quarz Ollanta y tambo la entraña más Germina la puerta Poroto cuadrado de sacro ser (...) Del templo a la tela Pinturea la cola (...) (vv. 2432, 35-37, pp. 26 y 27).
\end{abstract}

La acción de la puerta "de germinar" y la expresión "poroto cuadrado" remiten a las protuberancias en los muros de Ollantaytambo, que $\mathrm{Pa}-$ ternosto comenta en Piedra abstracta (1989); para él, estos elementos fueron dejados a propósito en los muros, pues contenían un significado que no se ha podido desentrañar; según su hipótesis, el sistema de las protuberancias sería análogo al sistema de nudos de los quipus (pp. 140-143).

Luego, se poetiza el paso del zorro desde estos centros ceremoniales antiguos a la tela, la que junto a la pintura de la cola recuerda el oficio de pintor de Paternosto. La dureza "pórfida" de la piedra se funde con la ligereza y suavidad de la pintura, formando una nueva pareja de opuestos complementarios.

En la sección "Reflejos" reaparecen las imágenes de la vicuña y el zorro en un texto en el que se unen la voz enunciante y algunas citas sobre la cultura andina; la primera de ellas es de Flores Ochoa, en relación con el origen mítico de alpacas y vicuñas, las que se habrían generado en los manantiales $^{13}$, y la cita que cierra el texto es de Bernabé Condori y Rosalin Gow, estudiosos de las culturas andinas, los que aseguran que la vicuña "es el animal de la tierra" (v. 14, p. 83), acentuando la conexión del animal con las ofrendas a los dioses.

De esta forma, la vicuña se asocia tanto al agua como a la tierra, y además, al oro, pues es una "mina / de oro" (vv. 5-6, p. 83), por su lana. Por ello, la vicuña es un animal de relevancia espiritual, "se la invoca al orar” (v. 7, p. 83), así como también es un pilar económico, en tanto es sustento para los pueblos andinos.

13 En el texto original, este origen mítico sólo correspondería a la alpaca: "No se sabe bien el origen de la alpaca, pero dicen que en el may timpu (en los orígenes de la humanidad), salieron de los manantiales y de los sitios donde hay agua, cerca de los nevados y que en el futuro, también se volverán a ir por los mismos manantiales" (Parte del testimonio de F. Q., de la Cordillera de Canchis, en Flores Ochoa, 1977, p. 219). 
El texto siguiente en la sección "Reflejos" es una cita del jesuita Bernabé Cobo (15821657), autor de Historia del Nuevo Mundo, obra referida a la botánica y a las culturas indígenas de América. En la cita, Cobo se refiere a dinámica natural entre zorros y vicuñas: los zorros devoran a las crías de vicuñas, pero estas defienden a patadas y en grupo a sus vástagos, asesinando al cazador. Este relato se enmarca en la idea de dualidades antagónicas y complementarias que preside la cosmogonía andina y se manifiesta en el texto. Las categorías de presa y predador, son, pues, intercambiables.

\section{El colibrí y el jaguar: intermediarios de los dioses}

La otra pareja de animales de $L a$ Wik'uña remite a las dicotomías debilidad-fuerza, pequeño-grande, aire-tierra; se trata del colibrí1 ${ }^{14}$ y el jaguar ${ }^{15}$, animales presentes tanto en el imaginario andino como en el guaraní. La cultura oral guaraní también se caracteriza por establecer un modelo binario de pensamiento, construido a partir de opuestos complementarios (Pacheco, 1992, p. 130).

El tercer texto del poemario es el "Canto del Colibrí" que pertenece a la tradición de los chiripá, grupo étnico guaraní $^{16}$. Este canto destaca la cualidad de iridiscencia de las plumas del ave al ser iluminadas por los rayos solares:

¿Tienes algo que comunicar, Colibrí?

¡Lanza rayos el Colibrí!

-El jugo de tus flores, evidentemente

te ha mareado, Colibrí (...)

(vv. 1-4, p. 15)

La iridiscencia de las plumas es un atributo divino para los guaraníes, como comenta Cadogan (1965) a propósito del "Canto del Colibrí":

Este canto es ejemplo de los guaú aí, poemas cortos cuyas figuras centrales son un pájaro o un cuadrúpedo. Encierran reminiscencias míticas y palabras arcaicas. El Colibrí, ave mítica, es el consejero de los augures y el portador de los mensajes de los dioses. Los relámpagos, atributo de los dioses, le acompañan, y le marea el "néctar de las flores", nombre religioso de la chicha que se consume durante la dan$z a$ ritual y la fiesta del guaú. (s.p., cursivas del texto)

$\mathrm{Al}$ igual que la vicuña y el zorro, el colibrí es un animal conectado con los dioses, intermediario entre estos y los seres humanos ${ }^{17}$; a esta situación de "gozne" entre lo terrenal y lo espiritual se alude en el canto a partir de una acción con doble trasfondo, pues el colibrí se alimenta del polen (terrenal), pero también de la chicha ritual (espiritual). El poema que sucede al "Canto del Colibri" en La Wik'uña es "Tentenelaire Zun Zun", título conformado de un neologismo, que remite al vuelo del colibrí ("mantenerse en el aire"), y la onomatopeya del batir de sus alas.

El poema celebra la relación entre el colibrí y la luz: el ave es un "espejo / que vuela" (vv. 6-7, p. 17), debido a la iridiscencia; al igual que la vicuña, el colibrí es metaforizado como un "oro"; se relaciona con el aire, las alturas y los dioses.

El poema mantiene la condición intermedia del colibrí,

14 Los colibríes son "de las aves más pequeñas en el mundo, con un peso de entre 1.7 y 20 gramos, de colores vivos y vuelo vibratorio, hacia adelante y hacia atrás, que aletean a una velocidad de hasta 80 circulaciones por segundo. El mayor número de especies se encuentra en los contrafuertes andinos más lluviosos de Venezuela, Colombia, Ecuador y Perú, siendo Colombia y Ecuador los países que tienen el 'récord mundial', con más de 120 especies” (Diario Electrónico Publimetro, 2011, s.p.).

15 "Tanto en Mesoamérica como en los Andes, el felino (jaguar o puma) es el depredador cuyas fauces reaparecen constantemente en las caras divinas (...)" (López Austin y Millones, 2010, p. 149).

16 “A grandes rasgos pueden distinguirse entre los guaraníes 'monteses' o no cristianizados tres grupos principales: mbyá, chiripá y pai-kaiová" (Cadogan, 1965, s.p.).

17 López Austin (Cadogan, 1965) comenta que para los guaraníes las aves pertenecen a los dioses, principio análogo al de la cosmovisión andina, en lo referente a los animales signados como rebaño de los dioses: "Las aves son seres domésticos de los dioses, por lo que poseen bienaventuranza y habitan en un paraíso en el que se encuentra el Verdadero Padre de los Pájaros. Vienen a la tierra periódicamente a criar" (s.p.). 
entre lo material y lo espiritual, en tanto vincula la imagen de succionar néctar con la de beber licor ritual: "Altarcito / licor" (vv. 13-14, p. 17); el colibrí no solo se nutre del polen, sino también de la luz: "Traga néctar / lumbrón” (vv. 4-5, p. 17). Este último neologismo aúna la luz y la cualidad de "lambrón" (goloso) del colibrí con respecto al néctar. A pesar de su fragilidad, el colibrí es poderoso al estar en relación con los dioses y cumplir una función importante en el reino animal, es por ello que basta su figura para evocar la dualidad complementaria terrenal-espiritual.

Al igual que la vicuña, el colibrí está en peligro de extinción ${ }^{18}$; esta situación ecológica se poetiza en "Guanambí Tominejo El Último Colibrí”, texto que a partir de onomatopeyas -"chinchorros", "chirridos"- evoca el zumbido del ave y presenta una imagen contemporánea: los colibríes revoloteando en un basural, en el que se distinguen sus reflejos:

Desecho rubiando
En el basural Bailando
un reflejo ¡Todos
se irán! (vv. 30-36, p. 76).

La asociación del colibrí con la basura implica la devaluación de lo natural en la cultura de las ciudades contemporáneas, en las que las aves han sido despojadas de su hábitat natural y de su condición sagrada.

En el apartado "Reflejos" se reitera la urgencia ante el peligro de extinción: “Tienes que apurarte, / nos estamos acabando' / dice el colibrí" (vv. 1-3, p. 96). El texto consigna dos experiencias citadinas con los colibríes, a los que la hablante llama por el nombre común en Chile, "picaflor":

En Quito vi picaflores que seguían las luces

del tránsito como un camión (...)

En Santiago los vi haciendo su danza nupcial en el basurero de Conchalí: los machos echando reflejos rojos (...)" (vv. 4-5, 7-9, p. 96).

A pesar de estar fuera de su hábitat, el colibrí sigue conectado con la luz y el fenómeno de la iridiscencia.

Un elemento interesante del poemario en relación con el colibrí es su conexión con la figura del chamán; uno de los textos de la sección "Reflejos" se abre con una cita de María Sabina: "Mujer colibrí soy" (p. 82), frase que forma parte de un cántico que ella entonaba al tomar hongos: "Mujer araña soy; mujer colibrí soy; mujer de un lugar sagrado y encantado soy; yo soy más que humano" (Pancorbo, 2011, p. 199). El poema de Vicuña se refiere a la figura del chamán como "Mensajero iridiscente" (v. 3, p. 82), pues tal como el colibrí es el mensajero de los dioses, el chamán es un intermediario entre fuerzas espirituales y los seres humanos.

El opuesto y complemento del colibrí es el jaguar, cuya imagen se recrea en el poema "yaguareté" (jaguar). El texto crea un contraste cromático entre el entorno y el animal:

$$
\begin{aligned}
& \text { Polvo } \\
& \text { de estrellas negras } \\
& \text { en un cielo } \\
& \text { de luz (vv. 1-4, p. 71) }
\end{aligned}
$$

La hablante enfatiza la rapidez y sigilo del animal, cuyo movimiento sobre la presa se corresponde con la muerte:

$$
\begin{aligned}
& \text { ¡Saltan } \\
& \text { las rayas } \\
& \text { Y es la muerte } \\
& \text { fugaz! (vv. 7-10, p. } 71 \text { ) }
\end{aligned}
$$

A pesar de que el jaguar es un cazador, la hablante se refiere a él con dulzura y cercanía, "Niño / de huerto" (vv. 16-17, p. 72), "mijito frutal" (v. 28, p. 73), y destaca su condición de sagrado: "Sacramento / es tu cuerpo" (vv. 21-22, p. 73).

En la sección "Reflejos" el jaguar reaparece en una asociación con el espejo, de la cual derivan conexiones con

18 La extinción, según los expertos, se debe a "la deforestación y otros factores propios de los modernos sistemas de cultivo" (Diario Electrónico Publimetro, 2011, s.p.). 
los reflejos, la iridiscencia, las deidades, los líderes y la espiritualidad. La hablante le llama al jaguar "Tigre espejo" (v. 1, p. 95), por el reflejo del sol en su pelaje: "Pelo que aprendió a reflejar" (v. 2, p. 95); en el texto se "teje un hilo" a partir de la palabra "espejo", armando una red poética y semántica que conecta diversas cosmogonías indígenas (nahua, huichol, maya):

Tezcatlipoca, "espejo que humea", el jaguar nahua, ve por el espejo del corazón

"Espejo del pueblo", el líder maya "ve la verdad"

Nen, (maya), algo que brilla $\mathrm{y}$ tiene poder

Niérika, el espejo huichol, puerta cósmica entre las realidades y "cara de dios" (vv. 4-10, p. 95).

En esta red de significados, que ante todo constituye un entramado poético, la palabra espejo, analogía del jaguar, es un signo ubicado entre la realidad y lo inasible (la "cara de dios"); el jaguar, como animal sagrado o animal-dios, es otro intermediario entre lo material e inmaterial, tal como el colibrí, aunque sea opuesto a este. Sus cualidades traspasadas a personas implican un poder singular que distingue al favorecido.

En suma, los animales que se poetizan están interconectados en el ecosistema americano y se consideran sagrados en las cosmogonías indígenas, pues son intermediarios entre el ser humano y las divinidades. Todos los animales se asocian con los reflejos de la luz, y con la escritura poética, lo que se evidencia en el siguiente texto:

$$
\begin{aligned}
& \text { El poema es el animal } \\
& \text { Hundiendo la boca } \\
& \text { En el manantial (p. 19) }
\end{aligned}
$$

La íntima conexión entre el animal sediento y el agua genera la escritura poética, que se configura como el reflejo del animal en el agua mientras bebe. En este sentido, cabe plantearse que la poesía de Vicuña es, tal como los animales, un vehículo de lo sagrado, que en la sencillez de diferentes elementos naturales descubre los misterios de la vida.

\section{Conclusiones}

Queda de manifiesto la relevancia de las cosmovisiones indígenas en la obra de Cecilia Vicuña, a partir del análisis de uno de los temas relevantes de su poemario La Wik'uña, las imágenes de los animales y su disposición en la obra, de acuerdo con el principio $H a$ nan / Hurin. Cada uno de los animales poetizados posee una connotación sagrada en tanto son cercanos a los dioses y mensajeros de estos. Asimismo, son, en su mayoría, animales en peligro de extinción, lo que se relaciona con la consciencia ecológica de la poeta, manifiesta también en la obra.
Los animales se organizan en parejas a partir del binarismo presa/ predador, sin embargo, esta oposición se plasma en tanto complementariedad, e incluso, en tanto categorías intercambiables, recíprocamente necesarias para perpetuar la vida. Esta primera oposición se complejiza al unirse al binarismo terrenal / espiritual, pues los cuatro animales constituyen figuras "gozne", situadas entre su condición terrena, que permite la subsistencia de su ecosistema, y su carácter espiritual de mediadores. De esta manera, los animales trascienden los encasillamientos en una u otra categoría, desplazándose desde lo material hacia lo inmaterial.

En el caso de la primera pareja, la vicuña y el zorro, llama la atención la presencia de elementos autobiográficos que complementan la simbología indígena; la vicuña, que extratextualmente remite al apellido de la poeta, la representa en su relación con el zorro, figuración de su marido en la obra. Es así como La Wik'uña rescata una forma de organización del mundo, las dualidades complementarias, que esta poesía considera absolutamente vigente, en tanto existen elementos contemporáneos que la actualizan.

Además, la presencia de los animales en el poemario resulta un metatexto de la escritura poética de Cecilia Vicuña, pues 
la identificación entre la poesía y el animal, este último entendido de acuerdo a las cosmovi- siones indígenas mencionadas, sugiere el carácter espiritual de esta poesía, que busca la tras- cendencia y lo genuino de la vida en los elementos sencillos de lo natural.

\section{Referencias}

Arrate, M. (junio de 2002). El brazo y la cabellera (Algunas disquisiciones sobre poesía escrita por mujeres en Chile). Revista de crítica cultural. Santiago: Art and Criticism Monograph Series, Art \& Text Publications, 24, 84-89.

Ariz, Y. (2010). Entrevista con Cecilia Vicuña. Revista Litterae. Recuperado de http://www2.udec. $\mathrm{cl} / \sim$ litterae/entrevista.html

Bianchi, S. (1990). Un mapa por completar: la joven poesía chilena. En S. Bianchi, Poesía chilena (Miradas - Enfoques - Apuntes). (pp. 37-88). Santiago: Cesoc.

Brito, E. (1998). Antología de poetas chilenas. Confiscación y silencio. Santiago: Dolmen.

Cadogan, L. (1965). La literatura de los guaranies. Introducción, selección y notas de A. López Austin. México: Joaquín Mortiz. Recuperado de Biblioteca Virtual del Paraguay http:/ /bvp-org-py.clasishopping.com/biblio_htm/cadogan/indice.htm

Calderón, T., Calderón L. y Harris, T. (1996). Veinticinco años de poesía chilena (1970-1995). México: Fondo de Cultura Económica. (30 de octubre de 2011). Colibríes, en peligro de extinción en América. Diario electrónico Publimetro. Recuperado de http://www.publimetro.com.mx/noticias/ colibriesen-peligro-de-extincion-en-america/mkjD!Q0bNUr1Y4CCYU/

Fariña, S. (1995). Una reflexión mestiza desde la escritura de cuatro mujeres chilenas. Antofagasta: Ediciones Universitarias, Universidad Católica del Norte.

Flores Ochoa, J. (1968). Los Pastores de Paratía: una introducción a su estudio. México: Instituto Indigenista Interamericano.

Flores Ochoa, J. (1977). Pastores de la Puna. Perú: IEP ediciones.

García García, J. J. (1996). Racionalidad de la cosmovisión andina. Lima: Consejo Nacional de Ciencia y Tecnología, CONCYTEC.

Granda Paz, O. (1998). Mito y arte prebispánico en los Andes. México: Instituto Latinoamericano de Investigaciones Estéticas.

Lichtenstein, G., Oribe, F., Grieg-Gran, M., Mazzucchelli, S. (2002). Manejo comunitario de vicuñas en el Perú. Recuperado de http://www.cites.org/eng/prog/economics/vicunas-peru.pdf 
López Austin A. y Millones, L. (2010) Dioses del Norte, Dioses del Sur. Religión y cosmovisión en Mesoamérica y los Andes. México: Era.

Martínez, C. (2004). El círculo de la consciencia: Una introducción a la cosmovisión indígena americana. En A. M. Llamazares y C. Martínez (Eds.), El lenguaje de los dioses. Arte, chamanismo y cosmovisión indígena en Sudamérica. (pp. 21-65). Buenos Aires: Biblos.

Pacheco (1992). La comarca oral. Caracas: La Casa de Bello.

Pancorbo, L. (2011). Los dioses increíbles. Madrid: Siglo XXI.

Paternosto, C. (1989). Piedra abstracta. La escultura inca: una visión contemporánea. México: Fondo de Cultura Económica.

Reyes, L. A. (2009). El pensamiento indígena en América. Los antiguos andinos, mayas y nabuas. Buenos Aires: Biblos.

Vicuña, C. (1990). La Wik’uña. Santiago: Francisco Zegers editor. 